\title{
Hu14.18-IL2 Fusion Protein EMD 273063
}

National Cancer Institute

\section{Source}

National Cancer Institute. Hu14.18-IL2 Fusion Protein EMD 273063. NCI Thesaurus.

Code C2509.

A recombinant protein consisting of the hu14.18 monoclonal antibody fused to the cytokine interleukin-2 (IL2) with potential antineoplastic activity. The monoclonal antibody portion of the hu14.18-IL2 EMD 273063 fusion protein binds to tumor cells expressing the GD2 antigen (melanoma, neuroblastoma and certain other tumors); the Fc component of the fusion protein antibody moiety and natural killer (NK) cells mediate antibody-dependent cell-mediated cytotoxicity (ADCC) and complement-dependent cellular cytotoxicity (CDCC) towards GD2-expressing tumor cells. The localized IL2 moiety of the fusion protein stimulates NK and T-cell antitumor cellular immune responses. 